Toxicological studies of Astavarga Kvatha Curna, an Ayurvedic formulation, on liver function parameters of rat plasma

\title{
Biology and Medicine
}

K Hamid, KF Urmi, MS Kabir, MO Ullah, MSK Choudhuri Accepted: $12^{\text {th }}$ Mar 2012, Published: $6^{\text {th }}$ Apr 2012 
www.biolmedonline.com

\title{
Toxicological studies of Astavarga Kvatha Curna, an Ayurvedic formulation, on liver function parameters of rat plasma
}

\author{
${ }^{*}$ K Hamid ${ }^{1}$, KF Urmi ${ }^{2}$, MS Kabir ${ }^{2}$, MO Ullah ${ }^{3}$, MSK Choudhuri ${ }^{2}$ \\ ${ }^{1}$ Department of Pharmacy, East West University, Dhaka, Bangladesh. \\ ${ }^{2}$ Department of Pharmacy, Jahangirnagar University, Dhaka, Bangladesh. \\ ${ }^{3}$ School of Chemistry and Molecular Biosciences, University of Queensland, QLD, Australia.
}

*Corresponding Author: kaiserpharm_1134@yahoo.com, kaiserpharm@gmail.com

\begin{abstract}
Astavarga Kvatha Curna (AST) approved by the National Unani and Ayurvedic Formulary Committee of Bangladesh is widely used in the treatment of vata roga (neurological disorder) by the rural and ethnic people of this country. In the present study, the effect of this formulation on liver function parameters of rat plasma was examined after chronic administration. The animal used was albino rat (Rattus novergicus: Sprague-Dawley strains) and the drug was administered per oral route at a dose of $40 \mathrm{ml} / \mathrm{kg}$ body weight, once daily, up to 41 days for all the experiments. Forty rats, equally of both sexes, were randomly grouped into four where one male and one female group were used as control and other groups were used as test. In both male and female rats, there was a statistically significant increase in the total protein (male, $p=0.044^{*}$, female, $\left.p=0.043\right)^{*}$. In case of albumin, the increase in the male rats were statistically significant $(p=0.003)^{* *}$ but it was statistically highly significant $(p=0.001)^{* * *}$ in the female rats. In case of SGOT, sGPT and ALP, there was a statistically highly significant $(p=0.001)^{* * *}$ increase in both male and female rats. The level of bilirubin was decreased in both male and female rats and it was statistically highly significant $(p=0.001)^{* * *}$.
\end{abstract}

Keywords: Astavarga Kvatha Curna (AST); liver function parameters; Ayurvedic formulation; rat plasma.

\section{Introduction}

Ayurveda, the traditional system of medicine, is regarded as the most methodical and efficient among all such systems practiced in different parts of the world. Because of the complexity and the adverse effects associated with the use of chemical drugs, much of the world's population is turning toward alternative systems of medicine. And the demand for plant based medicine has increased many folds in both developing and developed countries (Chopra et al., 2002; Mukharaji, 2000). Although the traditional and complimentary method of treatment may have health benefits and are normally practiced safely, over recent years there have been several concerns raised over the safety of some forms of complementary medicine, traditional/herbal medicines in particular (Bayly et al., 1995; Ernst, 2002).

In fact, there are many issues that are related to a lack of scientific evidence about the efficacy and safety of herbal remedies remains unresolved (Malik et al., 2003; Shekelle et al., 2005). Many reports and warnings have been published, particularly about the potential hepatotoxicity of herbal products, because the liver is a prime target for the toxic effects of general drugs (Stickel et al., 2001; Williams et al., 2002; Ahn, 2004).
Desmet (2004) mentioned six main categories of safety issues that relate to traditional/herbal medicines. They are:

1. The product may contain intrinsically toxic constituents to which the patient may be exposed (i.e., toxic ingredients or other undeclared components);

2. The product may contain contaminants from the preparation of the product (i.e., undeclared pharmaceuticals or heavy metals because of poor quality of manufacture or lack of quality control);

3. Self-administration of alternative therapies in preference to conventional medicines may result in the patient delaying seeking professional medical advice, or even abandoning conventional treatment altogether (Brienza et al., 2002);

4. Traditional or herbal medicines may compromise the efficiency of any conventional medicines that are being taken simultaneously (i.e., via drug-herb interactions) (Desmet, 2004);

5. Specific patient groups may particularly be at risk from traditional/herbal medicines (i.e., children, the elderly and pregnant or nursing mothers);

6. Patients with particular diseased states that may be at risk (e.g., those with cardiovascular 
or neurological illness that could be made worse).

Astavarga Kvatha Curna is an Ayurvedic formulation that is included in the Bangladesh National Formulary (BNF) of Ayurvedic Medicine (1992). It is widely used in the treatment of vata roga (neurological diseases) in the country. Actually, it is a preparation of eight important medicinal plants that were used in equal amount (Table 1).

Taking into consideration the safety concern of Ayurvedic medicines, our research group systematically working on the toxicological studies of different Ayurvedic formulations of Bangladesh by evaluating their effects on liver, kidney and lipid profile parameters of rat plasma after chronic administration. Previously, we reported the effects of Rohitakarista (Ullah et al., 2008; Ullah et al., 2010), Ardhabilva Kvatha Curna (Hamid et al., 2010) and Laghobanondo Rosh (Hamid et al., 2010). In the present study, the effects of AST on liver function parameters of rat plasma after its chronic administration have been reported.

\section{Materials and Methods}

Drugs, chemicals and reagents

For the toxicological study, Astavarga Kvatha Curna (AST) was collected from Sri Kundeswari Aushadhalaya Ltd, Chittagong. All other reagents, assay kits and chemicals used in this work were purchased from Sigma Chemical Co., St Louis, MO, USA.

Preparation of sample

Astavarga Kvatha Curna is included in the Bangladesh National Formulary of Ayurvedic Medicine (BNFAM) 1992. This formulary is compiled by the National Unani and Ayurvedic Formulary Committee and published by the Bangladesh Board of Unani and Ayurvedic Systems of Medicine, 38, Bangabandhu Avenue, Dhaka-1000 under the authority vested in the Board vide section 13 (j) of the Bangladesh Unani and Ayurvedic Practitioners Ordinance (1983) in collaboration with the World Health Organization.

A notification vide letter no. DA/Admin/1-10/96/6212 has been issued by the Directorate of Drug Administration on 19th October 1996. It has issued license under Drug Act (1940) and rules under Drug (Control) Ordinance (1982) for local manufacture and sale in Bangladesh. It is prepared following the method mentioned in the BNFAM (1992) and list of ingredients used in the preparation is mentioned in Table 1.

\section{Experimental animals}

Forty eight-week old albino rats (Rattus novergicus; Sprague-Dawley strain) of both sexes, bred and maintained at the animal house of the Department of Pharmacy, Jahangirnagar University, were used in the toxicological experiment. These animals were apparently healthy and weighed $50-70 \mathrm{~g}$. The animals were housed in a well-ventilated hygienic experimental animal house under constant environmental and adequate nutritional conditions throughout the period of the experiment. All of the rats were kept in plastic cages having dimensions of $30 \times 20 \times$ $13 \mathrm{~cm}$ and soft wood shavings were employed as bedding in the cages. They were fed with rat chow prepared according to the formula developed at Bangladesh Council of Scientific and Industrial Research (BCSIR). Water was provided ad libitum and the animals maintained at $12 \mathrm{~h}$ day and $12 \mathrm{~h}$ night cycle. All experiments on rats were carried out in absolute compliance with the ethical guide for care and use of laboratory animals approved by Ethical Review Committee, Faculty of Life Sciences, Jahangirnagar University.

\section{Experimental design}

In all the experiment a total of forty rats of both sexes were used. The rats were divided into four groups of ten animals where two were male groups and other two were female groups. For both of the sexes, one group was treated with AST and another was used as a control. The control animals were administered with distilled water only as per the same volume as the drug treated group for 41 days. For all the pharmacological studies the drugs were administered per oral route at a dose of $40 \mathrm{ml} / \mathrm{kg}$ body weight. After acclimatization, AST preparation was administered to the rats by intra-gastric syringe between 10 am and 12 pm daily throughout the study period.

\section{Blood samples collection and preparation of} plasma

At the end of 41 days treatment, after $24 \mathrm{~h}$ fasting, blood samples were collected from post vena cava of the rats anaesthetizing with Ketamine $(500 \mathrm{mg} / \mathrm{kg}$ body, intra peritoneal) and transferred into heparinised tubes immediately. Blood was then centrifuged at 4,000 $g$ for 10 min using bench top centrifuge (MSE Minor, England). The supernatant serum samples were collected using dry Pasteur pipette and stored in the refrigerator for further analyses. All analyses were completed within $24 \mathrm{~h}$ of sample collection.

Determination of liver function parameters 
Biochemical analysis was carried out on serum, to assess the state of the liver. Biochemical studies involved analysis of parameters such as total protein, serum albumin, bilirubin (total and direct), serum glutamic pyruvic transaminase (sGPT), serum glutamic oxaloacetic transaminase (sGOT) and alkaline phosphatase (ALP). Total protein content of the samples was assayed by the Biuret method (Plummer, 1971). Serum albumin concentration was determined using the method of Doumas et al. (1971). Serum bilirubin was determined according to the method of Evelyn and Malloy (1938). sGPT, sGOT, and ALP were determined by following the method of King and King (1954). The absorbances of all the tests were determined using spectrophotometer (UV-Visible Spectrophotometer Model No. UV-1601 PC).

\section{Statistical analysis}

The group data are expressed as Mean \pm SEM (Standard Error of the Mean). Unpaired "t" tests were done for statistical significance. SPSS (Ver. 11) for Windows was applied for the analysis of data. Differences between groups were considered significant at $p<0.05$, 0.01 and 0.001 .

\section{Results and Discussion}

In case of male rats, all the studied parameters were increased except bilirubin (Table 2). The increase was statistically significant in case of total protein $\left(p=0.044^{*}\right)$ and albumin $(p=0.003)^{\star *}$ but it was highly significant in case of sGPT $(p=0.001){ }^{* \star *}$ sGOT $(p=0.001)^{\star \star *}$ and ALP $(p=0.001)^{\star \star *}$ in comparison with the control group. Almost similar trend of results were observed in the female rats (Table 3 ). Except bilirubin, all the parameters were increased. In case of total protein it was statistically significant $(p=0.043)^{*}$. On the other hand, the increase of other parameters were statistically highly significant as sGPT $(p=0.001)^{* * *}$ sGOT $(p=0.001)^{* * *}$ and ALP $(p=0.001)^{* * *}$. Unlike male rats, the increase in albumin $(p=0.001)^{* * *}$ was statistically highly significant in case of female rats.

Table 1: Formulary of Astavarga Kvatha Curna (AST).

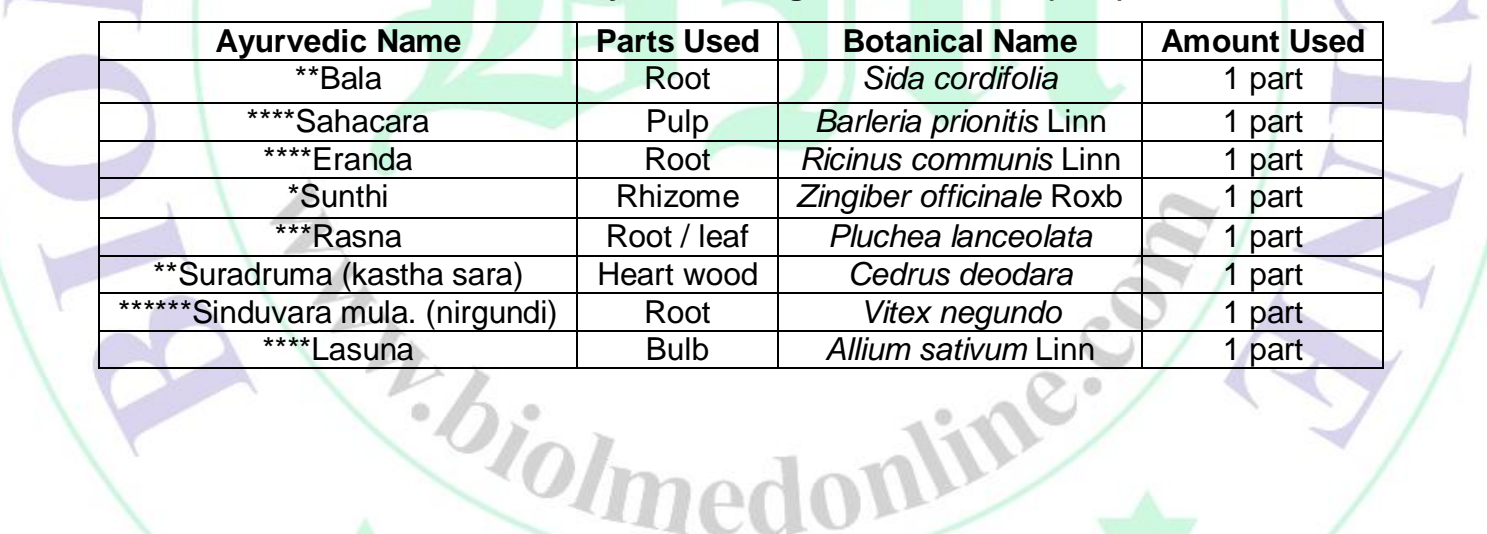

Table 2: Effect of AST on liver function parameters of male rat plasma after chronic administration $(40 \mathrm{ml} / \mathrm{kg})$.

\begin{tabular}{|c|c|c|c|c|}
\hline \multirow{3}{*}{ Parameters } & \multicolumn{2}{|c|}{ Male rats } & \multirow{3}{*}{$\%$ Changes } & \multirow{3}{*}{$p$ value } \\
\hline & \multicolumn{2}{|c|}{ Mean \pm SEM } & & \\
\hline & Control $(n=10)$ & Test $(n=10)$ & & \\
\hline Total protein & $6045.1490 \pm 96.0151$ & $6398.9552 \pm 76.3461$ & $5.85 \%$ increase & $p=0.044^{*}$ \\
\hline Albumin & $4814.2776 \pm 118.9384$ & $5203.5899 \pm 99.5845$ & $8.08 \%$ increase & $\mathrm{p}=0.003)^{* *}$ \\
\hline Bilirubin & $0.1318 \pm 0.00331$ & $0.0480 \pm 0.003498$ & $-63.58 \%$ decrease & $\mathrm{p}=0.001)^{* * *}$ \\
\hline sGPT & $59.8897 \pm 0.1283$ & $64.7002 \pm 0.1013$ & $8.03 \%$ increase & $\mathrm{p}=0.001)^{\star \star *}$ \\
\hline sGOT & $103.342 \pm 0.2832$ & $111.1183 \pm 0.1884$ & $7.52 \%$ increase & $\mathrm{p}=0.001)^{\star * *}$ \\
\hline ALP & $42.4660 \pm 0.1033$ & $44.9288 \pm 0.0784$ & $5.80 \%$ increase & $\mathrm{p}=0.001)^{\star * *}$ \\
\hline
\end{tabular}

In each group, 10 male rats were taken; $p$ values were calculated using unpaired t-test in comparison to control. * $p<0.05$, ${ }^{* *} p<0.01,{ }^{* * *} p<0.001 ; \mathrm{NS}=$ Not Significant. 
Table 3: Effect of AST on liver function parameters of female rat plasma after chronic administration $(40 \mathrm{ml} / \mathrm{kg})$.

\begin{tabular}{|c|c|c|c|c|}
\hline \multirow{3}{*}{ Parameters } & \multirow{2}{*}{\multicolumn{2}{|c|}{$\begin{array}{l}\text { Female rats } \\
\text { Mean } \pm \text { SEM }\end{array}$}} & \multirow{3}{*}{$\%$ Changes } & \multirow{3}{*}{$p$ value } \\
\hline & & & & \\
\hline & Control $(n=10)$ & Test $(n=10)$ & & \\
\hline Total protein & $5102.0477 \pm 125.3468$ & $5484.3082 \pm 71.1231$ & $7.49 \%$ increase & $\mathrm{p}=0.043)^{*}$ \\
\hline Albumin & $3996.996 \pm 72.9053$ & $5266.8186 \pm 59.8262$ & $31.76 \%$ increase & $\mathrm{p}=0.001)^{\star \star \star}$ \\
\hline Bilirubin & $0.09058 \pm 0.003932$ & $0.05806 \pm 0.001857$ & $-35.90 \%$ decrease & $\mathrm{p}=0.001)^{\star * \star}$ \\
\hline sGPT & $56.0077 \pm 0.1461$ & $59.8184 \pm 0.1629$ & $6.80 \%$ increase & $\mathrm{p}=0.001)^{\star \star \star}$ \\
\hline sGOT & $95.5919 \pm 0.2212$ & $99.5274 \pm 0.2066$ & $4.12 \%$ increase & $\mathrm{p}=0.001)^{\star * *}$ \\
\hline ALP & $39.2208 \pm 0.1085$ & $42.2508 \pm 0.1314$ & $7.73 \%$ increase & $\mathrm{p}=0.001)^{* * *}$ \\
\hline
\end{tabular}

In each group, 10 female rats were taken; $p$ values were calculated using unpaired t-test in comparison to control. ${ }^{*} p<0.05$, ${ }^{* *} p<0.01,{ }^{* * *} p<0.001 ; N S=$ Not Significant.

Hepatic cells participate in a variety of metabolic activities and contain a host of enzymes. In tissues, sGOT and sGPT are found in higher concentrations in cytoplasm and sGOT in particular also exists in mitochondria. In liver injury, the transport function of the hepatocytes is disturbed, resulting in the leakage of plasma membrane, thereby causing an increased enzyme level in serum, and soluble enzymes like sGOT will also be similarly released. The elevated activities of SGOT and SGPT in serum are indicative of cellular leakage and loss of functional integrity of cell membranes in liver (Rajesh and Latha, 2004). Alkaline phosphatase is excreted normally via bile by the liver. In liver injury due to hepatotoxin, there is a defective excretion of bile by the liver which is reflected in their increased levels in serum (Singh et al., 1998). These results indicate the impaired liver function after the administration of AST.

The decreased level of bilirubin in plasma indicated lack of toxic effect on liver even after chronic administration of AST. According to Naganna (1989), increase in bilirubin indicates abnormal liver function which may be the result of higher synthetic function of the liver. On the other hand, hyperbilirubinaemia is often the first and sometimes the only manifestation of liver disease. Impaired hepatic bilirubin clearance due specifically to reduced uptake or possible competition for binding to 2-protein or ligandin (Lee and Garner, 1983). So the decreased level of bilirubin indicates normal function.

\section{Conclusion}

AST is an Ayurvedic formulation widely used by the rural and ethnic people in Bangladesh for the treatment of vata roga (neurological disorder). In the present study, it is observed that the chronic administration of this drug increases all the enzymes indicating impaired liver function. On the contrary, it decreased level of bilirubin indicating normal liver function. So it necessitates further detailed study for finding out the reason behind it.

\section{Ethical Approval}

The study was approved by the Ethical Review Committee, Faculty of Life Sciences, Jahangirnagar University.

\section{Conflict of Interests}

Authors have no conflicting interests.

\section{Acknowledgement}

The authors are thankful to Mr. Shafiqur Rahman for his technical assistance during the course of research work.

\section{References}

Ahn BM, 2004. Herbal preparation-induced liver injury. Korean Journal of Gastroenterology, 44: 113125.

Bayly GR, Braithwaiter RA, Sheehan TMT, Dyer $\mathrm{NH}$, Grimley C, Ferner RE, 1995. Lead poisoning from Asian traditional remedies in the West Midlands - report of a series of five cases. Human \& Experimental Toxicology, 14(1): 24-28.

Brienza RS, Stein MD, Fagan MJ, 2002. Delay in obtaining conventional healthcare by female internal medicine patients who use herbal therapies. Journal of Women's Health and Gender Based Medicine, 11(1): 79-87.

Chopra A, Doiphode V, 2002. Ayurvedic medicine: core concept therapeutic principles, and current relevance. Medical Clinics of North America, 86(1): 75-89. 
Desmet PAGM, 2004. Health risks of herbal remedies: An update. Clinical Pharmacology \& Therapeutics, 76(1): 1-17.

Doumas BT, Watson WA, Biggs HG, 1971. Albumin standards and measurement of serum-albumin with bromocresol green. Clinica Chimica Acta, 31(1): 8796.

Ernst E, 2002. Heavy metals in traditional Indian remedies. European Journal of Clinical Pharmacology, 57(12): 891-896.

Evelyn KA, Malloy HT, 1938. Microdetermination of Oxyhemoglobin, Methemoglobin and Sulfhemoglobin in a single sample of blood. Journal of Biological Chemistry, 126: 655-662.

Hamid K, Kabir MS, Ullah MO, Bulbul IJ, Siddiqua M, Choudhuri MSK, 2010. Effect of Ardhabilva Kvatha Curna, an ayurvedic formulation, on liver and kidney function parameters of rat plasma after chronic administration. Biology and Medicine, 2(3): 49-57.

King PRN, King EJ, 1954. Estimation of plasma phosphatase by determination of hydrolysed phenol with amino-antipyrine. Journal of Clinical Pathology, 7(4): 322-326.

Kaplan AP, 1965. Urea nitrogen and urinary ammonia. In: Standard Method of Clinical Chemistry, Meites S. Academic Press Inc., New York, 245-256.

Latha U, Rajesh MG, Latha MS, 1999. Hepatoprotective effect of an Ayurvedic medicine. Indian Drug, 36: 470-473.

Lee KS, Garner LM, 1983. Management of unconjugated hyperbilirubinaemia in the newborn. Seminars in Liver Disease, 3(1): 52-56.

Mukharaji KP, 2002. Quality Control of Herbal Drug. $1^{\text {st }}$ edition. New Delhi; Business Horizon Publication, 6-13.

Malik IA, Gopalan S, 2003. Use of CAM results in delay in seeking medical advice for breast cancer. European Journal of Epidemiology, 18: 817-822.
Naganna B, 1989. Plasma proteins. In: Textbook of Biochemistry and Human Biology. Talwar GP, Srivastava LM, and Moudgil KD. Prentice-Hall of India Private Ltd., New Delhi, 2nd edition, 59-61.

Plummer DT, 1971. An Introduction to Practical Biochemistry. McGraw-Hill, London, 2nd edition, 144-145.

Rajesh MG, Latha MS, 2004. Protective effect of Glycyrrhiza glabra Linn. on carbon tetrachlorideinduced peroxidative damage. Indian Journal of Pharmacology, 36: 284-286.

Siddiqua M, Hamid K, Rashid MHA, Akther MS, Choudhuri MSK, 2010. Changes in lipid profile of rat plasma after chronic administration of Laghobanondo Rosh (LNR) - an ayurvedic formulation. Biology and Medicine, 2(3): 58-63.

Shekelle PG, Morton SC, Suttorp MJ, Buscemi N, Friesen $\mathrm{C}, 2005$. Challenges in systematic reviews of complementary and alternative medicine topics. Annals of Internal Medicine, 142: 1042-1047.

Stickel F, Seitz HK, Hahn EG, Schuppan D, 2001. Liver toxicity of drugs of plant origin. German Journal of Gastroenterology, 39: 225-232, 234-237.

Ullah MO, Hamid K, Rahman KA, Choudhuri MSK, 2010. Effect of Rohitakarista (RHT), an ayurvedic formulation, on the lipid profile of rat plasma after chronic administration. Biology and Medicine, 2(2): 26-31.

Ullah MO, Uddin MJ, Hamid K, Kabir S, Rahman MA, Choudhuri MSK, 2008. Studies of various biochemical parameters of rat plasma following chronic administration of "Rohitakarista"- an ayurvedic formulation. Pakistan Journal of Biological Sciences, 11(16): 2036-2039.

Williams GM, latropoulos MJ, 2002. Alteration of liver cell function and proliferation: differentiation between adaptation and toxicity. Toxicologic Pathology, 30: 41-53. 